\title{
Our experience in the surgical management of craniofacial fibrous dysplasia: what has changed in the last 10 years?
}

\author{
La nostra esperienza nel trattamento chirurgico della displasia fibrosa \\ cranio-maxillo-facciale: cosa è cambiato negli ultimi 10 anni? \\ V. VALENTINI' ${ }^{1}$, A. CASSONI' ${ }^{1}$ V. TERENZI ${ }^{1}$, M. DELLA MONACA ${ }^{1}$, M.T. FADDA ${ }^{1}$, O. RAJABTORK ZADEH ${ }^{1}$, \\ I. RAPONI' 1 A. ANELLI' , G. IANNETTI' \\ 'Odontostomatological Science and Maxillofacial Surgery Department, "Sapienza" University of Rome. Policlinico Umberto \\ I, Rome, Italy; ${ }^{2}$ Otolaryngology-Head and Neck Surgery Dept, National Cancer Institute "Regina Elena", Rome, Italy
}

\begin{abstract}
SUMMARY
The mainstay of treatment of craniofacial dysplasia (CFD) remains surgery once clinical observation has been excluded. Nevertheless, disagreement remains about the type of surgical intervention (remodelling versus radical resection). The aim of this paper is to present our experience until 2013 comparing CFD management between 1980 and 2002 and between 2003 and 2013 and to propose our surgical algorithm. From January 2003 to December 2013, 41 new patients (18 males and 23 females) with histologically demonstrated CFD presented to our Department. Data were compared with those of 95 patients observed and/or treated between 1980 and 2002 . Considering the last period, we noted that observation (26/41 patients) was the most used method; radical resection was performed in most cases (8/15 patients), but in proportion the numbers of patients undergoing bone shaving has increased (6\% between 1980 and 2002 vs $15 \%$ between 2003 and 2013), while a decrease in the number of patients undergoing excision was seen (63\% between 1980 and 2002 vs. $19 \%$ between 2003 and 2013). On this basis, we believe that radical resection is the only technique to obtain resolution of fibrous dysplasia. Wait-and-see is indicated in case of stable lesions. Reconstructive techniques allow obtaining adequate aesthetical and functional results; nevertheless, in most cases adjunctive surgical refinements are required and recovery time is higher than with surgical shaving, so that most patients prefer to perform remodelling. Nevertheless, in case of aggressive lesions radical resection is mandatory, except in paediatric patients with residual large defects in which it can be acceptable to try to resolve symptoms via bone shaving, reserving more aggressive treatments in case of relapse or after skeletal maturity.
\end{abstract}

KEY WORDS: Craniofacial fibrous dysplasia $\bullet$ Free flap $\bullet$ Paediatric reconstruction $\bullet$ Surgical treatment

\section{RIASSUNTO}

Nonostante la chirurgia rimanga l'opzione di scelta nel trattamento della displasia cranio-facciale (CFD) una volta che l'osservazione clinica sia stata esclusa, resta controverso il tipo di intervento (rimodellamento contro resezione radicale). Lo scopo di questo lavoro è di rivedere criticamente la nostra esperienza fino al 2013 confrontando la gestione CFD tra il 1980 e il 2002 e tra il 2003 e il 2013 e di proporre il nostro algoritmo chirurgico. Dal gennaio 2003 al dicembre 2013, 41 nuovi pazienti (18 maschi e 23 femmine) con diagnosi di CFD sono stati considerati. I dati sono stati confrontati con quelli di 95 pazienti che sono stati osservati e / o trattati tra il 1980 e il 2002. Considerando l'ultimo periodo abbiamo notato che l'osservazione clinica (26/41 pzt) è stato il metodo più utilizzato; una resezione radicale è stata eseguita in molti casi $(8 / 15 \mathrm{pzt})$, ma in proporzione il numero di pazienti sottoposti a rimodellamento è aumentato $(6 \% \mathrm{vs}$ $15 \%)$, mentre è stato osservato una diminuzione del numero di pzt sottoposti escissione (63\% vs 19\%). Su queste basi, riteniamo che la resezione radicale rimanga l'unica tecnica per ottenere la risoluzione della displasia fibrosa. L'osservazione clinica è indicata in caso di lesioni stabili. Le moderne tecniche ricostruttive consentono di ottenere adeguati risultati estetici e funzionali in caso di resezione radicale; tuttavia, nella maggior parte dei casi si rendono necessarie ulteriori procedure ed i tempi di recupero sono superiori, cosicchè la maggior parte dei pazienti preferiscono eseguire il rimodellamento. Nonostante tutto, in caso di lesioni aggressive la resezione radicale è mandatoria, tranne che in pazienti pediatrici in cui tale intervento comporterebbe estesi difetti residui: in tali casi può essere accettabile effettuare un rimodellamento riservando trattamenti più demolitivi in caso di recidiva o dopo la maturità scheletrica.

PAROLE CHIAVE: Displasia fibrosa cranio-maxillo-facciale $\bullet$ Lembi liberi $\bullet$ Ricostruzione in età pediatrica $\bullet$ Trattamento chirurgico 


\section{Introduction}

Fibrous dysplasia (FD) is a non-malignant bone lesion characterised by replacement of normal bone with fibroosseous connective tissue. It was first described by Von Recklinghausen in 1981 as "osteitis fibrosa generalisata" $^{12}$. In 1938, Lichtenstein and Jaffe introduced the term "fibrous dysplasia", differentiating between the monostotic and polyostotic types (MFD and PFD, respectively) ${ }^{3}$. The McCune-Albright syndrome (MAS) was described in $1937^{45}$; in these cases, the polyostotic form is associated with precocious puberty and areas of cutaneous pigmentation (cafè au lait spots). The term craniofacial dysplasia (CFD) has been introduced to describe forms arising in the contiguous bones of the cranium and facial skeleton; therefore, it cannot be defined as either a monostotic or polyostotic type ${ }^{6}$. In cases of MFD, the zygomatic-maxillary complex is reported to be the region most commonly involved. In cases of PFD and MAS, the anterior cranial base is involved in the disease in more than $95 \%$ of cases ${ }^{78}$. Even if medical therapy has a role in the management of symptoms, the mainstay of treatment remains surgery (radical or conservative). Clinical observation is recommended in cases of asymptomatic, slow-growing lesions that do not compromise the quality of life.

We present our experience in 95 patients affected by FD involving craniofacial bones (1980-2002). Among these, we performed surgery in 68 cases. We present an update of our experience and propose our surgical algorithm in which we critically review our experience prior to 2013, and then compare FD management between 1980-2002 and 2003-2013.

\section{Materials and methods}

From January 2003 to December 2013, 41 new patients (18 males and 23 females) with histologically demonstrated fibrous dysplasia located in the cranio-maxillofacial area presented to our department. Medium followup was 51 months (range: 9-108 months). The average patient age was 29 years (range: 8-72 years). In 35 cases (85\%), patients presented with MFD as specified in our previous study; forms affecting two contiguous segments of bone were classified as monostotic, and thus, monostotic should be understood as meaning monofocal. Five patients (12\%) had PFD, while only one patient (3\%) was diagnosed with MAS. Considering the two periods examined (1980-2002 versus 2003-2013), differences between distribution of the FD type in the patient populations are illustrated in Figure 1A.

\section{Results}

Among these 41 patients, 15 (36.5\%) underwent surgery. When considering 95 patients that presented to our department between 1980 and 2002, a higher percentage (71.2\%) were surgically treated (68 patients). Management of FD according to the patients' group is illustrated in Figure 1B. Observation (26/41 patients) was the most widely used method in the last 10 years. This group consisted of 17 females and nine males with a median age of 31.5 years (range: $8-72$ ). Of particular interest was that nine paediatric patients $(34.6 \%)$ were present. In 22/26 patients, MFD was observed. Specific data are reported in Table I. None of these patients received treatment, since stable/low growing lesions were present and were not causing functional and/or important aesthetical discomfort.

In patients who underwent surgical treatment, radical resection was performed in most cases ( $8 / 15$ patients). However, the proportion of patients undergoing bone shaving increased (6\% versus 15\%), while a decrease in the number of patients undergoing radical surgery was seen $(63 \%$ versus $19 \%)$. Optic canal nerve decompression was performed in one only long-standing symptomatic patient, and a small amount of visual improvement was observed. Radical resection of a mandibular lesion was performed in two cases of relapse $(2 / 7 \mathrm{pa}-$ tients) after bone shaving (one case was performed at

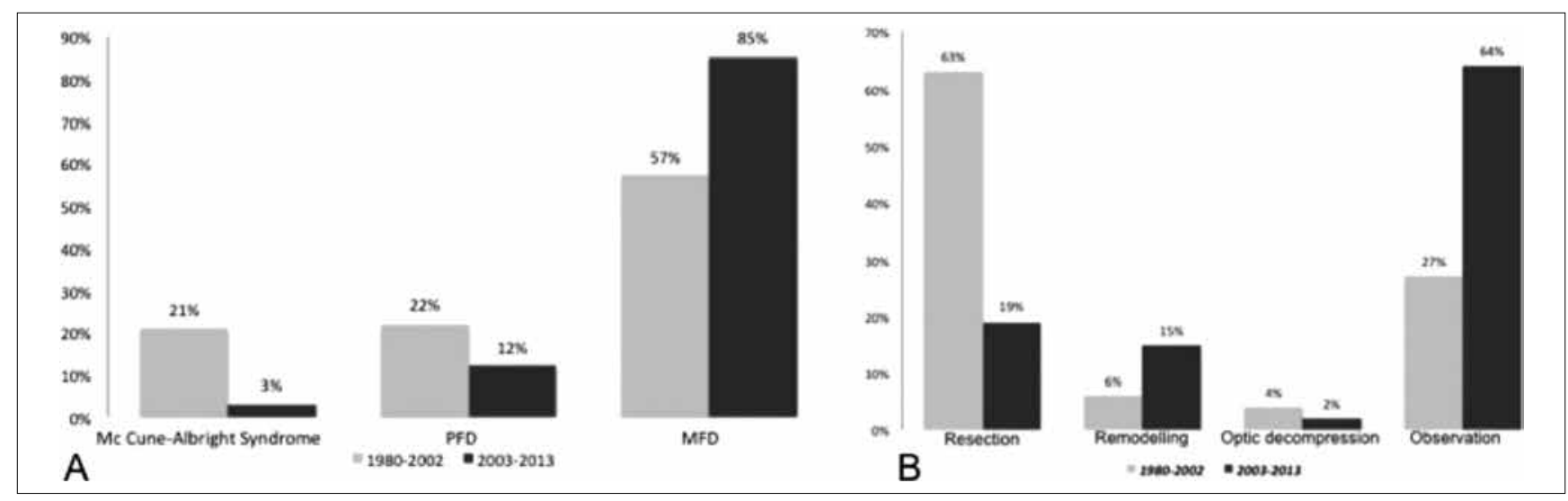

Fig. 1. Changes between 1980 and 2002 and between 2003 and 2013 in the treatment of FD. A) Distribution of FD type; B) Management of FD. 
Table I. DF characteristics in the observational group.

\begin{tabular}{lccc} 
Involved Area & Monostotic & Polyostotic & $\begin{array}{c}\text { Patient } \\
\text { Number }\end{array}$ \\
Mandible & 7 & 1 & 8 \\
Maxillary bone & 4 & 2 & 6 \\
Maxillary+Cheekbone & 1 & 1 & 2 \\
Ethmoid & 0 & 3 & 3 \\
Sphenoid & 6 & 3 & 9 \\
Frontal & 3 & 3 & 5 \\
Temporal & 0 & 1 & 1 \\
Total patients: 26 & & & \\
\hline
\end{tabular}

another centre). As previously reported, no relapse was observed after radical treatment.

\section{Discussion}

FD represents about $2.5 \%$ of all bone lesions and $7 \%$ of all benign bone tumours, with an incidence of 1:40001:10,000 with a slight female predilection; usually the disease arises in the first three decades of life and stabilises when patients reach skeletal maturity ${ }^{9}$. In most cases of CFD, the first clinical manifestation is a slow growing, eventually painful mass causing facial asymmetry. Pathological fractures, orbital dystopia, diplopia, proptosis, blindness, epiphora, strabismus, facial paralysis, loss of hearing, tinnitus and nasal obstruction, may also be evident. These lesions can infrequently present rapid growth and can be associated with other pathological lesions such as mucoceles or aneurysmal bone cysts, while malignant transformation is very rare $(<1 \% \text { of cases })^{8}$. On the basis of clinical behaviour, lesions can be classified as:

- quiescent (stable with no growth);

- non-aggressive (slow growing);

- aggressive (rapid growth +/- pain, para-aesthesia, pathologic fracture, malignant transformation, and association with secondary lesions).

Diagnosis can be made with X-ray and CT-scan, but an incisional biopsy is mandatory. Once FD is confirmed, it is important to exclude PFD and MAS. Serum alkaline phosphatase is an important marker in detecting recurrence of $\mathrm{FD}^{10}$.

Surgery is considered the mainstay of treatment once clinical observation has been excluded. In our experience over the last 10 years, we noted that observation has been the therapy of choice in cases of FD (63.5\% observational cases versus $28.8 \%$ surgery). In the last several years, medical therapy with biphosphonate (such as zoledronic acid) or an antibody to RANKL (such as denosumab) has been used to attempt to control pain and stabilise lesions, but long term effects are controversial ${ }^{10-15}$. Radiotherapy is excluded because of the high risk of malignant transformation ${ }^{8}$. At present, the main discussion is about the type of surgery, since radical resection is the only curative technique, while bone shaving allows achieving adequate aesthetic-functional results but is burdened by a higher recurrence rate ${ }^{7}$. In a previous study, we stated that "we prefer conservative treatment of fibrous dysplasia only in cases involving the cranial base, polyostotic forms, and McCune-Albright syndrome. On the other hand, in the majority of cases of MFD or monofocal fibrous dysplasia of the craniofacial region, we conclude that modern surgical techniques allow an aggressive but definitive treatment with good functional and aesthetic results." ?

In principle we still agree with this statement, but analysing the data on FD management (Figure 1B), we observed that in the last 10 years the number of patients undergoing bone shaving has increased (6\% versus $15 \%)$, while a decrease in number of patients undergoing radical surgery was seen (63\% versus $19 \%$ ). On this basis, we propose a more detailed surgical algorithm in which we specify that clinical observation is the first option. A first proposal for FD classification was suggested by Chen in $1990{ }^{16}$. He differentiated treatment on the basis of involved sites and defined four zones:

- Zone 1: fronto-orbito-malar regions of the face. Radical excision and reconstruction are recommended.

- Zone 2: hair bearing scalp. Intervention is optional.

- Zone 3: central skull base including the sphenoid, pterygoid, petrous temporal bone, and mastoid. Observation is recommended.

- Zone 4: tooth bearing portions of the skull, the maxilla and mandible. Conservative management is recommended.

As previous reported, we only partially agree with the algorithm proposed by Chen, since free flaps allow optimal results in the recontruction of Zone 4 defects; nevethless, at present, we have partially changed our opinion about the treatment of stable lesions involving Zones 1 and $4^{7}$. Another detailed description of CFD management according to anatomical sites has been recently proposed by Lee et $\mathrm{al}^{8}$. In this study, we present our algorithm based on pathological behaviour and symptoms.

\section{a) Facial deformities}

Most patients affected by CFD present a slow growing, indolent mass, and facial deformity is the only symptom. In most cases, disease progression stops once skeletal maturity has been achieved, but reactivation of the disease has been observed in adulthood and during pregnancy ${ }^{17}{ }^{18}$. Even in MAS cases, skull lesions preferentially do not progress after puberty. Deformities are more disfiguring than in MFD and PFD, particularly if GH excess is untreated or inadequately treated ${ }^{19}$. Management of FD depends on the anatomical site as well as on clinical and biological characteristics of lesions, but, especially in younger patients, it is impossible to predict it since no biomarkers or specific histological characteristics exist. In those latter cases, watching carefully and attentively is the best option. It is preferable to perform any 


\section{A- Pediatric patients}

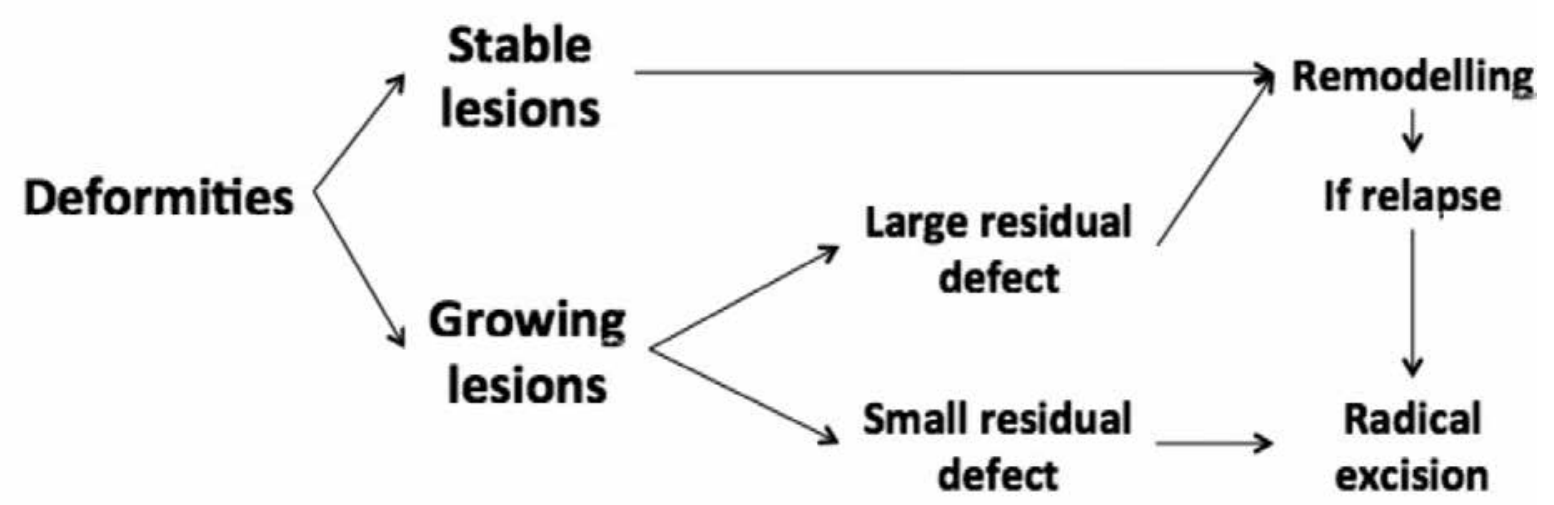

\section{B-Adult patients}

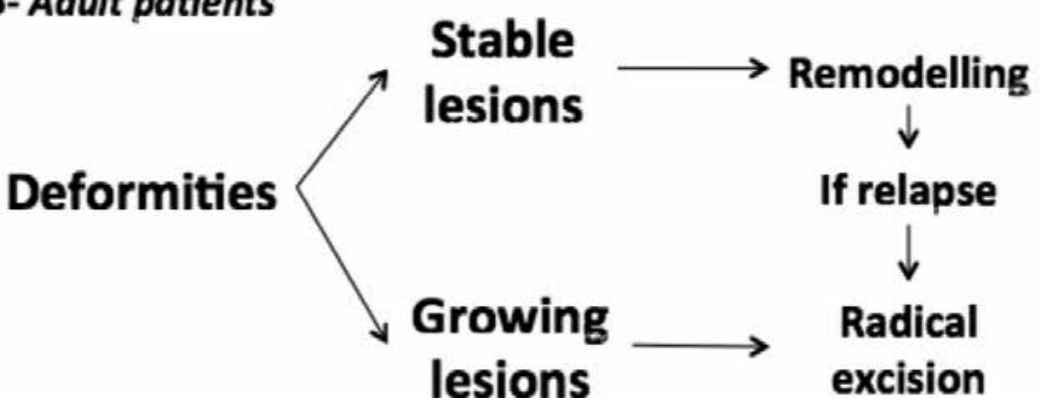

Fig. 2. Surgical management of facial deformities in adults (A) and children (B).

kind of surgery only after puberty, but sometimes it is necessary to operate on the patient earlier.

One of the main question concerns is the treatment choice and whether it is easier to treat an adult or a child. In our previous paper, we recommended wide resection and contemporary reconstruction in cases of Zones 1 and 4 lesions even in younger children ${ }^{7}$. While in cases of Zone 1 defects, reconstruction can be achieved in most cases using bone grafts and/or local flaps; in cases of Zone 4 defects, free flaps are preferential as they can assure adequate reconstruction, but in younger patients their use should be discussed ${ }^{2021}$. It is clear that it is more important to distinguish between adult ( $>14$ years) and paediatric ( $<14$ years) patients than between stable (quiescent/non-aggressive) and growing (aggressive) lesions. Considering both adult and paediatric populations with cases of stable lesions, we currently recommend remodelling as the primary treatment (Figs. 2A and B). It is true that a major rate of recurrence is reported after bone shaving, but it can be repeated.

An adequate follow-up (annual CT scan for the first two years and then based on of clinical findings) makes it possible to identify relapse and to treat it early. Obviously, in those latter cases the treatment of choice is surgical resection and contemporary reconstruction. The change in the treatment of stable lesions in adult patients is due to the fact that wide resection always requires reconstruction; this can lead to higher post-operative morbidity in terms of recovery time when compared to surgical shaving, even if the aesthetical and functional results are considered better.

Based on our advice, it is mandatory to inform the patient about the therapeutic options. In most cases, remodelling is the favoured choice. This is probably due to the fact that most patients prefer to try to obtain aesthetical and functional improvements with a less complex surgical intervention, knowing that in case of a relapse radical surgery can be performed.

In previous studies, reports on recurrence do not differentiate between stable and growing lesions; it can be hypothesised that in the first cases the expected recurrence rate would be lower. In paediatric patients, remodelling permits the clinician to avoid influencing craniofacial growth and asymmetry. Currently, surgical shaving can be optimised using computer-assisted navigation ${ }^{22}$. Mirroring techniques permit achieving optimal aesthetic results, but there appear to be some disadvantages. The main one is the absence of instruments in some centres. Due to the low use in maxillofacial surgery, operative time is higher than with conventional techniques ${ }^{23}$. 
In cases of aggressive lesions, it seems the best therapeutic option is surgical resection and contemporary reconstruction; nevertheless, in the case of paediatric patients each case has to be carefully evaluated according to several parameters:

- wide resection (mostly if altering occlusion) leads to some degree of facial asymmetry regardless of reconstruction;

- donor site morbidity must be considered.

We have to distinguish between two main situations:

- Small residual defects: Reconstruction can be achieved using local flaps or bone grafts, so that a radical resection can be considered. Since radiotherapy is not considered, treatment for CFD, complications related to bone grafts and absorption due to irradiation can be excluded. The best option in cases of mandibular reconstruction is the use of an autogenous rib graft. Such cases may require further surgical intervention (eventually with a free flap reconstruction) once skeletal maturity has been reached in order to permit implantoprosthetic rehabilitation ${ }^{24}$. In this group with Zone 1 defects, in which bone graft reconstruction leads in most cases to adequate results, can be included 162526 .

- Large residual defects: Even an adequate reconstruction can lead to facial asymmetry, and remodelling as the first choice should be considered, eventually delaying a more aggressive surgical intervention after puberty. Currently, free-tissue transfer has become the preferred treatment option for reconstruction of extensive tissue; iliac crest and fibula free flaps appear to be the best options in cases of Zones 1 and 4 defects in adults. Nevertheless, some considerations have to be made in younger patients, since the recipient vessels are much more prone to vasospasm compared to those in adults. In addition, one must consider growth alteration at the donor site. Iliac crest free flap is not considered before skeletal ma- turity has been reached ${ }^{20}$. Fibula free flaps are the best choice, and donor-site morbidity can be minimised in most cases with attention to technical details of fibular flap harvesting and use of aggressive physical therapy ${ }^{27}$. Nevertheless, even if some authors advocate its use also in younger patients ( $<9$ years), we think that in cases of surgical resection for malignant lesions immediate reconstruction using fibula free flap can be justified, but in FD cases this option has to be considered only after failure of primary reconstruction using bone grafts or in case of relapse after remodelling has occurred.

\section{b) Trigeminal nerve impairment}

Growing lesions can result in compression of the adjacent structure such as the trigeminal nerve; patients refer hypo-anaesthesia or para-aesthesia, but in some cases they complain of hyperaesthesia. In such cases, surgical decompression of the canal nerve has been described ${ }^{28}$. Nevertheless, this procedure cannot be definitive; in such cases, more aggressive intervention consisting of nerve interruption at the Spix or infraorbital foramen may be required. In order to restore sensitivity of the lip and teeth, a microsurgical anastomosis with the contralateral mandibular nerve can be performed at the same surgical time (Fig. 3). In cases of infraorbital nerve impairment, anastomosis can be performed using a nerve graft ${ }^{29}$.

\section{c) Sinusitis}

Between the paranasal sinuses, the sphenoid sinus is the most frequently affected by FD ${ }^{830}$. Nevertheless, the incidence of sinusitis in patients affected by FD is the same when compared with the general population ${ }^{8}$. The treatment is the same and consists of a combination of surgery and medical therapy (Fig. 4A); obviously, surgery is necessary to correct anatomical alterations causing obstruction or associated lesions such as mucocele ${ }^{18}$. A preferential approach, as in the general population, is an endoscopic one ${ }^{31}$. If aesthetical corrections are needed,

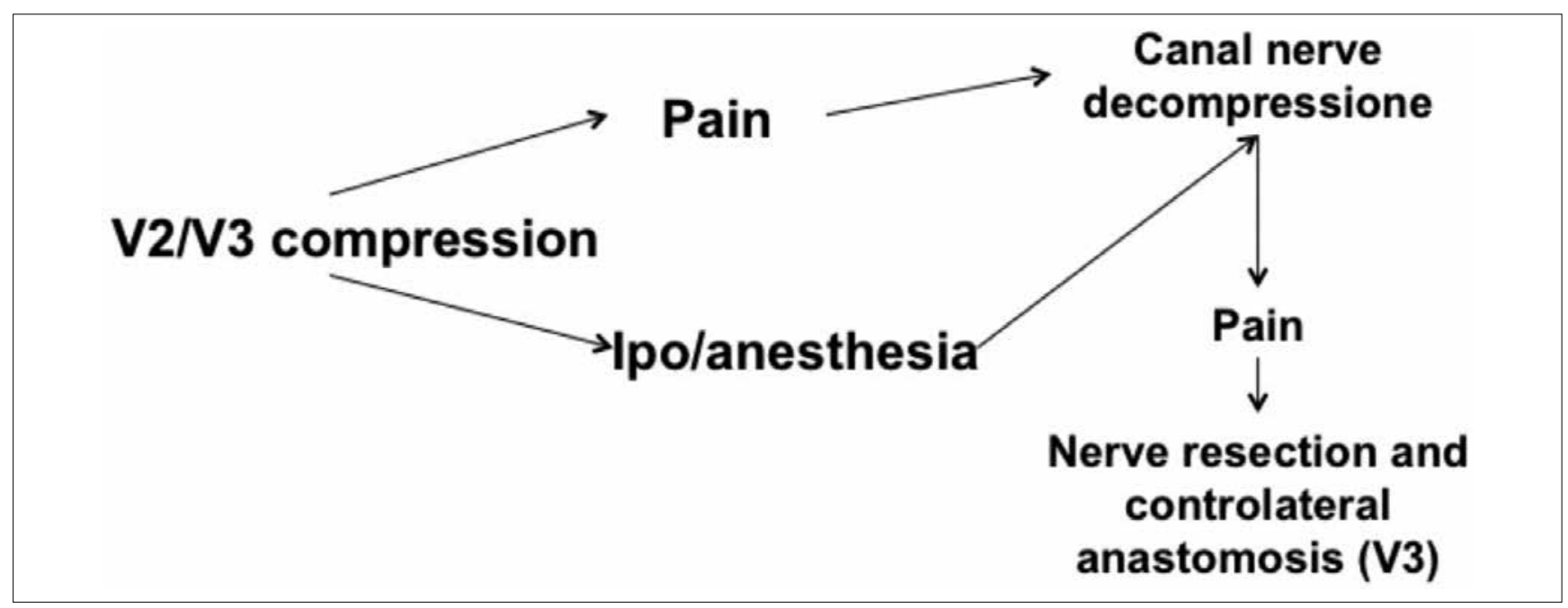

Fig. 3. Surgical management of V2/N3 impairment. 


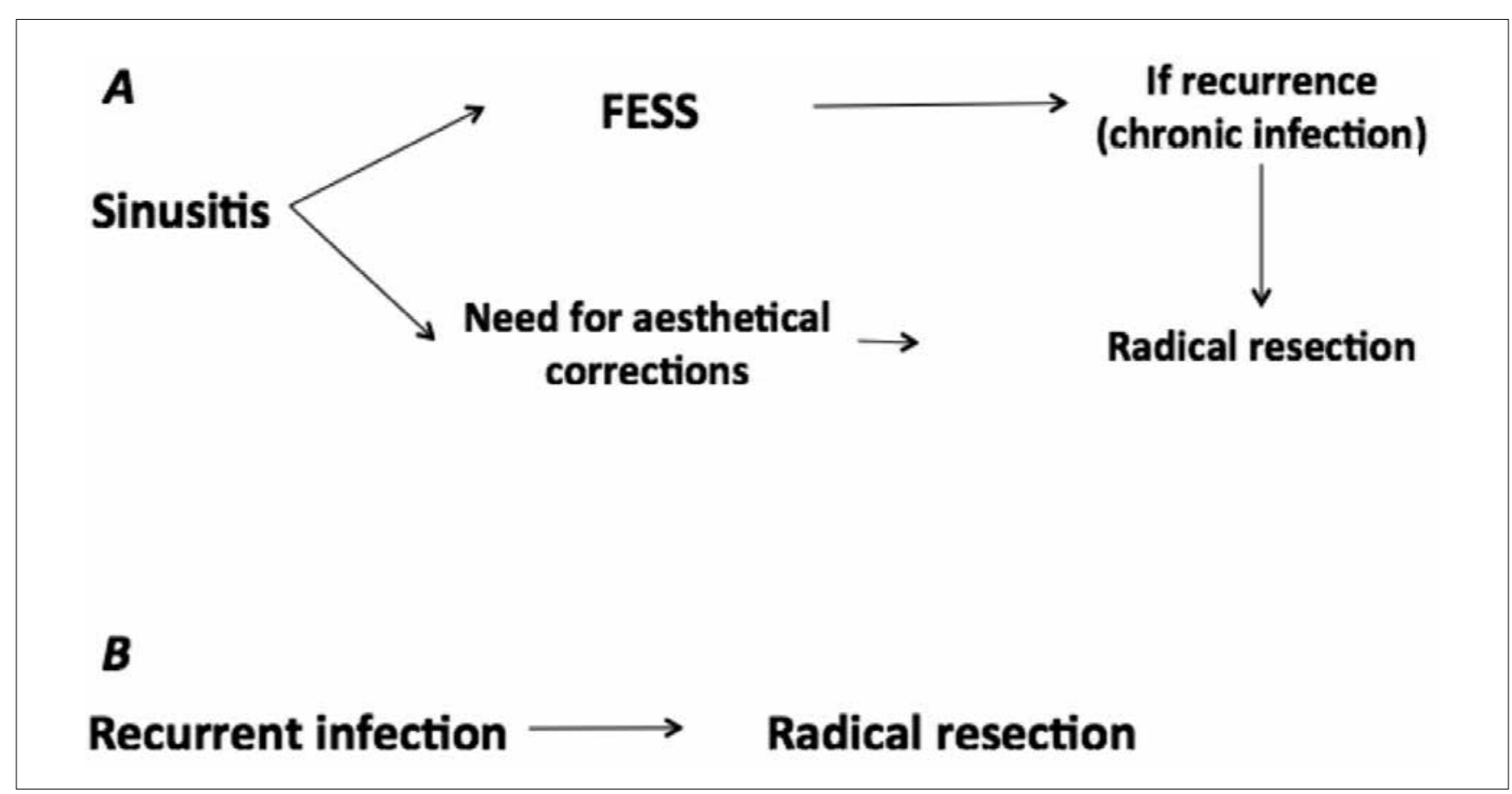

Fig. 4. Surgical management of sinusitis and of recurrent infections.

these should eventually be made in association with open access. In cases of recurrent sinonasal infection, particular attention must be paid to avoid complications such as osteomyelitis. In such cases, surgical resection is required. d) Osteomyelitis

In patients affected by FD, osteomyelitis is one of the complications that can arise. It is most frequent in case of lesions involving the maxilla and mandible derived from dental infections or recurrent sinusitis. Diagnosis can be difficult, since only histological examination can confirm it in most cases. It is very challenging to treat. Medical therapy is mandatory, but to resolve the pathology, surgical resection (Fig. 4B) is usually required ${ }^{8}$. It is known that caries index scores are higher in patients affected by FD, and this has been attributed to enamel hypoplasia and hypomineralisation, and also to limited dental care. In cases of dental infection, it is mandatory to extract or treat the teeth, but in these cases healing can be altered thus increasing the risk of osteomyelitis ${ }^{8}$.

\section{Diplopia/exophthalmos}

Orbital bone involvement in cases of CFD can lead to midfacial asymmetry or hypertelorism, exophthalmos and proptosis (in cases of anterior skull base and frontal bone involvement); diplopia can be referred. In the first case, treatment is described in the section "Facial deformities" and consists of remodelling in cases of stable lesions and wide resection in cases of aggressive ones. When massive involvement of the orbital bones is observed, an interdisciplinary approach is mandatory to evaluate the presence of ophthalmological complications such as diplopia and visual impairment ${ }^{32}$. In surgical treatment of exophthalmos consequent to FD, it must be considered that remodelling of maxilla and zygoma can lead to a worsening of symptoms. In those cases, surgical osteotomies to improve orbital volume should be performed (Fig. 5A). If only a 2-wall decompression is required, an endoscopic approach has to be considered ${ }^{33}$. Obviously, maxillo-zygomatic correction must be considered at the same surgical time. In order to treat diplopia, the first step is to correct orbital dystopia; eventually, eye muscle realignment surgery can be performed.

e) Optic nerve compression (ONC)

CFD involving the anterior cranial base and sphenoid bone can encase the optic nerve, but does not always result in visual loss. It is already accepted that loss of vision consequent to optic canal nerve involvement can be due to several factors, including direct compression, optic nerve traction (proptosis), haemorrhage/injury of the optic nerve and FD-associated cystic lesions ${ }^{34}$.

Recently, a meta-analysis concluded that most patients affected by CFD with radiographic optic nerve compression are asymptomatic and will remain that way, so that "....surgical decompression should be reserved for symptomatic patients, the majority of whom will show improvement and good long-term results after optic nerve decompression. Expectant management, repeated ophthalmologic exams, and long-term radiologic follow-up are indicated in asymptomatic FD patients who have optic nerve encasement." ${ }^{35}$. In cases in which decompression is required, we agree with Schreiber et al (Fig. 5B), who stated that “... endoscopic optic nerve decompression has become wide- 


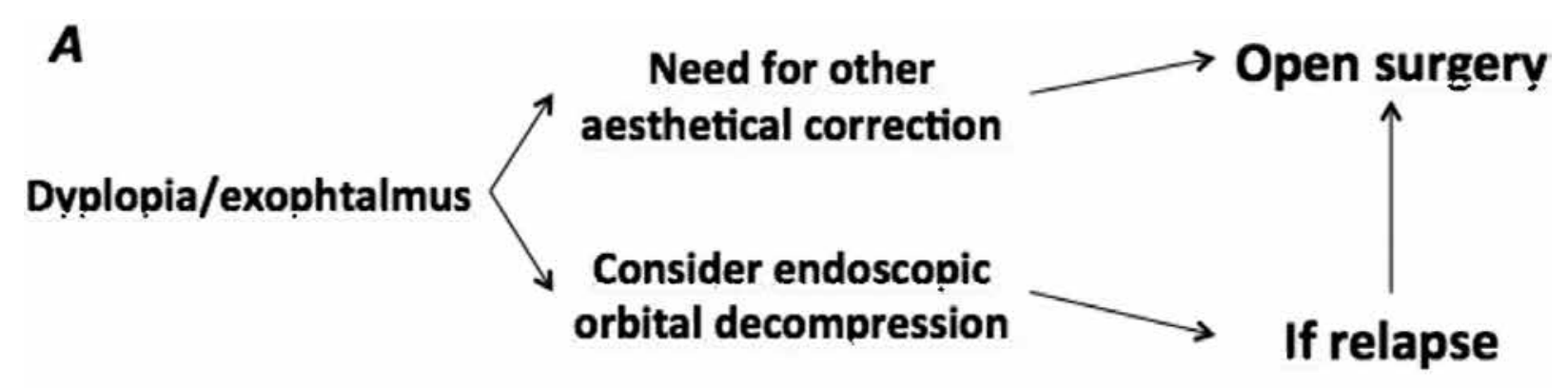

B
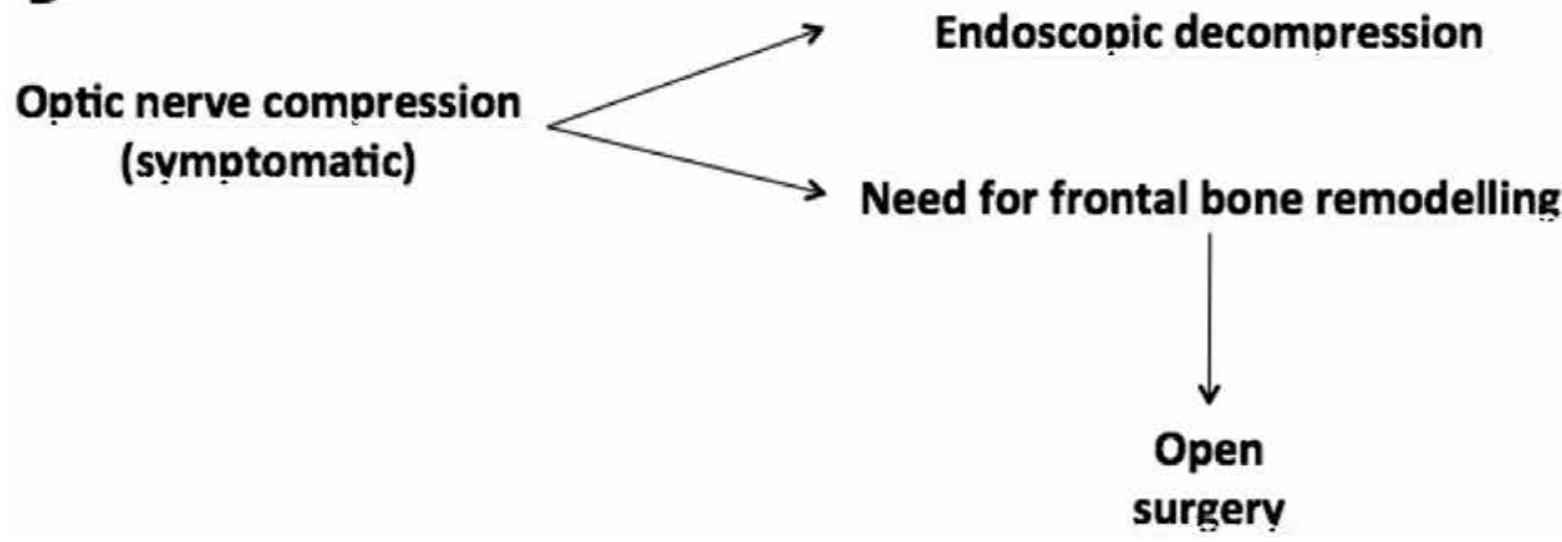

Fig. 5. Surgical management of diplopia/exophthalmos and optic nerve compression.

ly accepted as the approach of choice for post- traumatic injuries and subsequently for benign lesions compressing the nerve and accessible through the nose, such as fibrous dysplasia" ${ }^{18}$. Open surgery is reserved for cases in which a need for frontal bone or other anterior cranial base remodelling is required; obviously, a combined approach should eventually be considered.

\section{Conclusions}

Fibrous dysplasia is a benign disease and radical resection (if possible) is the only technique to obtain resolution of the disease. Watching carefully and attentively is indicated in cases of stable lesions, and based on our experience, it is the best therapeutic option if possible. Current reconstructive techniques allow achieving adequate aesthetic and functional results; nevertheless, in most cases adjunctive surgical refinements are required and recovery times are higher than in cases of surgical shaving, so that most patients prefer to undergo remodelling. Nevertheless, in cases of aggressive lesions we think that radical resection is mandatory, except in paediatric patients with residual large defects. In these cases, we think that it is acceptable to try and resolve symptoms by performing bone shaving, reserving more aggressive treatment for cases of relapse or after skeletal maturity.

\section{References}

1 Ozek C, Gundogan H, Bilkay U, et al. Craniomaxillofacial Fibrous dysplasia. J Craniofac Surg 2002;13:382-9.

2 Von Recklinghausen. FD: Die fibrose oder deformierende Ostitis, die Osteomalacie, und die ostoplastische Carcinose in ihren gegenseltgen Beziehungen. Berlin: Festschr, Rudolf Virchow; 1891.

3 Lichtenstein L, Jaffe HL. Fibrous dysplasia of bone: a condition affecting one, several or many bones, tha graver cases of which may present abnormal pigmentation of skin, premature sexual development, hyperthyroidism or still other extraskeletal abnormalities. Arch Pathol 1942;33:777.

4 McCune DJ. Osteitis fibrosa cystica: the case of a nine year old girl who also exhibits precocious puberty, multiple pigmentation of the skin and hyperthyroidism. Am J Dis Child 1936;52:743.

5 Albright F, Butler AM, Hampton AO, et al. Syndrome characterized by osteitis fibrosa disseminata, areas of pigmentation and endocrine dysfunction, with precocious puberty in females: report of five cases. N Engl J Med 1937;216:727.

6 Eversole LR, Sabes WR, Rovin S. Fibrous dysplasia: A nosologic problem in the diagnosis of fibro osseous lesions of the jaws. J Oral Pathol 1972;1:189-220. 
7 Valentini V, Cassoni A, Marianetti TM, et al. Craniomaxillofacial fibrous dysplasia: conservative treatment or radical surgery? A retrospective study on 68 patients. Plast Reconstr Surg 2009; 123:653-60.

8 Lee JS, FitzGibbon EJ, Chen YR, et al. Clinical guidelines for the management of craniofacial fibrous dysplasia. Orphanet J Rare Dis 2012;7Suppl1:S2.

9 Menon S, Venkatswamy S, Ramu V, et al. Craniofacial dysplasia: literature review. Ann Maxillofac Surg 2013;3:66-71.

10 Park BY, Cheon YW, Kim YO, et al. Prognosis for craniofacial fibrous dysplasia after incomplete resection: AGE and serum alkaline phosphatise. Int J Oral Maxillofac Surg 2010;39:221-6.

11 Chapurlat RD, Gensburger D, Jimenez-Andrade J, et al. Pathophysiology and medical treatment of pain in fibrous dysplasia of bone. Orphanet J Rare Dis 2012;7Suppl1:S3

$12 \mathrm{Wu} \mathrm{D}, \mathrm{Ma} \mathrm{J}$, Bao S, et al. Continuous effect with long-term safety in zoledronic acid therapy for polyostotic fibrous dysplasia with severe bone destruction. Rheumatol Int 2015;35:767-72.

13 Ganda K, Seibel MJ. Rapid biochemical response to denosumab in fibrous dysplasia of bone: report of two cases. Osteoporos Int 2014;25:777-82.

14 Thomsen MD, Rejnmark L. Clinical and radiological observations in a case series of 26 patients with fibrous dysplasia. Calcif Tissue Int 2014;94:384-95.

15 Boyce AM, Chong WH, Gafni RI, et al. Denosum$a b$ treatment for fibrous dysplasia. J Bone Miner Res 2012;27:1462-70.

16 Chen YR, Noordhoff MS. Treatment of craniomaxillofacial fibrous dysplasia: How early and how extensive? Plast Reconstr Surg 1990;86:835-42.

17 Lee, Davies ML, Macpherson P. Fibrous dysplasia of the skull: disease activity in relation to age. $\mathrm{Br} \mathrm{J}$ Radiol 1991;64:576-9.

18 Schreiber A, Villaret AB, Maroldi R, et al. Fibrous dysplasia of the sinonasal tract and adjacent skull base. Curr Opin Otolaryngol Head Neck Surg 2012;20:45-52.

19 Lala R, Matarazzo P, Andreo M, et al. Impact of endocrine hyperfunction and phosphate wasting on bone in McCune-Albright syndrome. J Pediatr Endocrinol Metab 2002;15:913-20.

20 Genden EM, Buchbinder D, Chaplin JM, et al. Reconstruction of the pediatric maxilla and mandible. Arch Otolaryngol Head Neck Surg 2000;126:293-300.

21 Weizman N, Gil Z, Wasserzung O, et al. Surgical ablation and free flap reconstruction in children with malignant head and neck tumors. Skull Base 2011;21:165-70.
22 Yu H, Shen SG, Wang X, et al. The indication and application of computer-assisted navigation in oral and maxillofacial surgery-Shanghai's experience based on 104 cases. $\mathrm{J}$ Craniomaxillofac Surg 2013;41:770-4.

23 Nowinski D, Messo E, Hedlund A, et al. Computer-navigated contouring of craniofacial fibrous dysplasia involving the orbit. J Craniofac Surg 2011;22:469-72.

24 Eckardt A, Swennen G, Barth EL, et al. Long-term results after mandibular continuity resection in infancy: the role of autogenous rib grafts for mandibular restoration. J Craniofac Surg 2006;17:255-60.

25 Gabbay JS, Yuan JT, Andrews BT, et al. Fibrous dysplasia of the zygomaticomaxillary region: outcomes of surgical interventation. Plast Reconstr Surg 2013;131:1329-38.

26 Valentini V, Cassoni A, Marianetti TM, et al. Reconstruction of craniofacial bony defects using autogenous bone grafts: a retrospective study on 233 patients. J Craniofac Surg 2007; 18:953-8

27 Crosby MA, Martin JW, Robb GL, et al. Pediatric mandibular reconstruction using a vascularized fibula flap. Head Neck 2008;30:311-9.

28 Bessho K, Tagawa T, Murata M, et al. Monostotic fibrous dysplasia with involvement of the mandibular canal. Oral Surg Oral Med Oral Pathol 1989;68:396-400.

29 Meyer RA, Bagheri SC. Microsurgical reconstruction of the trigeminal nerve. Oral Maxfac Surg Clin N Am 2013;25:287-302.

30 DeKlotz TKH. Otologic and sinonasal manifestations of PFD/MAS. Presented at the Combined Otolaryngology Spring Meeting Chicago, IL 2011.

31 Re M, Magliulo G, Romeo R, et al. Risks and medico-legal aspects of endoscopic sinus surgery: a review. Eur Arch Otorhinolaryngol 2014;271:2103-17.

32 Goisis M, Biglioli F, Guareschi M, et al. Fibrous dysplasia of the orbital region: current clinical perspectives in ophthalmology and cranio-maxillofacial surgery. Ophtal Plast Reconstr Surg 2006;22:383-7.

33 Choi JW, Lee SW, Koh KS. Correction of proptosis and zygomaticomaxillary asymmetry using orbital wall decompression and zygoma reduction in craniofacial fibrous dysplasia. J Craniofac Surg. 2009;20:326-30.

${ }^{34}$ Lee JS, FittzGibbon E, Butman JA, et al. Normal vision despite narrowing of the optic canal in fibrous dysplasia. $\mathrm{N}$ Engl J Med 2002;347:1670-6.

35 Amit M, Collins MT, FitzGibbon EJ, et al. Surgery versus watchful waiting in patients with craniofacial fibrous dysplasia-a meta-analysis. PLoS ONE 2011;6:e25179. 